Thursday, 21 July

Time: 10:30 AM

Session Number: 6.8: Organizational Issues and Processes

Session Chair: Gountas, Sandra, Curtin University

Inter-organizational Supply Chain Performance: How the Relationship Factors Influence the Australian Beef Industry?

Nasir Uddin, Mohammad, Curtin University of Technology

Quaddus, Mohammed, Curtin University of Technology

Islam, Nazrul, Department of Agriculture and Food, WA

A Typology of Relational Processes in Egyptian Companies : An Exploratory Study

Yacout, Omneya, Alexandria University

Understanding the New, Negotiated Phase of Relationship Marketing: A Proposed

Research Agenda

Schultz, Don, Northwestern University

Malthouse, Edward, Northwestern University

Pick, Doreen, Freie Universität Berlin

Discussion Leader: Sanjaya, Gaur, Auckland University of Technology 


\title{
INTER-ORGANIZATIONAL SUPPLY CHAIN PERFORMANCE: HOW THE RELATIONSHIP FACTORS INFLUENCE THE AUSTRALIAN BEEF INDUSTRY?
}

\author{
Mohammad Nasir Uddin, Curtin University of Technology, Australia \\ Mohammed Quaddus, Curtin University of Technology, Australia \\ Nazrul Islam, Department of Agriculture \& Food WA and Curtin University of Technology, Australia
}

\begin{abstract}
This study examines supply chain structures and inter-organizational relationship factors that influence the supply chain performance in the Australian beef industry. It investigated the extent to which aggregated relationship strength is a source of supply chain performance for the industry. The effect of antecedent factors such as vertical coordination, negotiation power and the use of IOS in the relationship strength were also investigated. Data were collected through a telephone survey in 315 firms including input suppliers, producers, processors and retailers in the beef industry of Western Australia and Queensland. The results support both the direction of theoretical underpinnings from RBV and TCE in the beef industry, that durable buyer-supplier relationships in the supply chain are developed from the level of commitment and trust, interdependence and mutual investment and can be a strategic economic resource to by-pass the cost of traditional market transactions. Results suggest the following key success factors for the beef industry in Australia: (a) the operational adoption of a lean supply chain between producer and processors or processors and retailers; (b) a transparent interdependent relationship with a strong consolidation/integration of business activities; and (c) synchronized information flows for greater compliance with carcass specifications in the supply chain.
\end{abstract}

\section{INTRODUCTION}

Supply chain management (SCM) in the Australian beef industry relates to all the linkages from the primary producers to the final consumers in the production and distribution of goods such as the management of producers, feed-lotters, slaughterers, processors, wholesalers and retailers in the beef industry. Supply chains in the Australian beef industry have been based on market arrangements with operations production pushed and often adversarial for which producers do not gain any insight to their customers as they are isolated from the rest of the food chain. Likewise, processors are lacking innovative initiatives to develop a product and the business with the producers while a low trust environment between the two often exists (O'Keeffe 1998; WY and Associates 2009). Studies found that these are the key issues affecting the performance, competitiveness and success of the industry, highlighting the need for improved information flow and relationship structure in the whole of supply chain participants (O’Keeffe 1998; Uddin, Quaddus, and Islam 2010).

Based on the above, three objectives were pursued in the research. First, we examine how supply chain structures and the use of inter-organizational systems influence inter-firm relationship strength and SC performance in the Australian beef industry. We use two constructs - 'negotiation power' and a higher order concept 'vertical coordination' to explore the current supply chain structures and their effects on the industry. Second, we examine the elements of relationship strength within the supply chain environments of the beef industry in two Australian states; Western Australian and Queensland. Using four elements of relationships in a higher order formative construct, we examine their individual contribution to forming relationship strength. Finally, we investigate the extent of strength of the aggregated relationship as a source of supply chain performance for the industry.

The next section presents the research background theories, and hypotheses. The research model and methodologies are discussed then, followed by a discussion of results. Finally, the paper concludes with a listing of implications from the results.

\section{CONCEPTUAL BACKGROUND AND HYPOTHESES}

\section{Vertical Coordination in the Supply Chain Relationship}

Transaction cost economics (TCE) is the most widely used theoretical lens for analyzing the development and impact of relationship structures and their governance in a food supply chain (Hobbs 2000; Williamson 1975, 1985). Based on the work of Williamson, studies have suggested that the methods of vertical coordination (VC) range from spot market, specification contracts, relation-based alliances and equity-based alliances to vertical integration. Often, it is argued that the time and costs involved for detecting a suitable buyer/seller, the quality and price of the saleable products are the reasons for more vertical coordination by circumventing the marketplace. Lawrence, Grimes, and Hayenga (1998) argued that quality of a product is 
one of the major concerns, especially in the meat industry, and requires an integrated information flow given that open markets are only very limitedly able to pass on quality-related information in food chains. TCE also recognizes that imperfect, incomplete or asymmetrical information between supply chain partners may increase opportunistic behavior and transaction costs. Finally, as one of the key variables in TCE is the degree of asset specificity, many authors argue that if the specific investment increases the spectrum of vertical coordination, there may be a move towards a more formal type of relationship such as vertical integration in the supply chain (Hobbs 2000; Peterson and Wysocki 1997; Williamson 1975, 1985). The result may be use of strategic alliances or long-term contracts or full vertical integration depending on the asset specific investment made by one party, or both, in a mutually agreed case for serving special market segments. Therefore, we hypothesise that

H1: The level of 'vertical coordination' in a supply chain positively influences the level of 'relationship strength' of the Australian beef industry.

H2: The level of 'vertical coordination' in a supply chain positively influences the level of 'SC performance' of the Australian beef industry.

\section{Negotiation Power in Supply Chain Relationships}

Power is defined as the ability of one firm to influence the intentions and actions of another firm (Maloni and Benton 2000) while negotiation power is related to the capacity of one party to influence others due to its size or status. Researchers have applied different power bases in supply chain relationships and found direct implications of power circumstances in a supply chain that have a significant affect on inter-firm relationships, and consequently, on chain performance. Studies suggest that there are specific supply chain power circumstances based on commitment, dominance and interdependence for which different relationship management approaches emerge. The current study assumes that to play a consequential role in the formation and maintenance of supply chain relationships, a firm should have some degree of negotiation power that may come from its cooperative arrangements, larger market share and/or brand penetration. A positive pro-active supply chain relationship is only enforceable, or be likely to emerge, when there is consistent direction in dominance or interdependence among the chain participants (Revell and Liu 2007).

Based on the above discussion we develop the following hypothesis:

H3: 'Negotiation power' in a supply chain positively influences the inter-firm 'relationship strength' of the Australian beef industry.

\section{IOS Use in Supply Chain Relationships}

Researchers have agreed that the use of inter-organizational systems (IOS) such as electronic data interchange (EDI), webbased procurement system, electronic trading system or supplier relationship management system can enhance coordination of the supply chain members, enhance information transfer and sharing and can reduce inter-firm transaction costs (contract, control and monitoring costs). Many researchers have used the framework of RBV (Resource-based view) to assert the contribution of IOS as an infrastructure and strategic resource that can provide greater scope for organizations to exploit their individual capabilities (Barney 2002; Borman 2006) such as strengthening the inter-firm relationship. IOS influences relationship strength because it can be a determinant of the level of trust, commitment and interdependence of supply chain partners (Ali, Kurnia, and Johnston 2007). It provides a link among the sources of information at different relationship levels and creates wider breadth and depth of information flow (Alavi and Leidner 2001). Based on the above discussion following hypotheses are developed

H4: The level of 'IOS use' in a supply chain positively influences the level of 'relationship strength' of the Australian beef industry.

H5: The level of 'IOS use' in a supply chain positively influences the 'SC performance' of the Australian beef industry in the Australian agri-food industry.

\section{Relationship Strength and Supply Chain Performance}

A large part of SCM literature consists of managing competent inter-firm or inter-organizational relationships such as alliances or partnerships in a supply chain to gain competitive advantage and firm performance. It has been argued that high quality relationships can be based on willingness to invest and it may have greater trust, commitment or interdependence with 
the notion of continuing it for a longer term for a greater cost saving in SC transactions. The lack of emphasis in supply chain relationships may decline competitiveness in the marketplace while cooperative planning and information sharing in the relationship may lead the entire chain to being a source of strategic competitive advantage (Clare, Reid, and Shadbolt 2005). In the agricultural industry chain, O'Keefe (1998) termed it as 'co-operating to compete', pointing to the shift of competition from firm versus firm to chain versus chain, wherein a firm can run more competitively if they work together within a supply chain in a cooperative environment. Thus, a coordinated supply chain relationship can reduce the risk and uncertainties in transactions and provide many returns such as lower product and/or service costs, enhanced quality and innovation, and a better firm performance (Golicic, Foggin, and Mentzer 2003). Based on the above discussion, it was hypothesized in the current study that perfect synergies of economic and behavioral factors such as reciprocal investment, interdependence, trust and commitment are related to the inter-firm relationship strength and will influence the performance of the beef industry, as follows:

H6: The 'strength of inter-firm relationships' in a supply chain positively influences the 'SC performance' of the Australian beef industry.

\section{THE RESEARCH MODEL}

The operational model is designed according to the hypotheses. It is developed and tested using the partial least square (PLS) based structural equation modeling (Chin, 1998). Figure 1 presents the latent variables and the hypothesized structural relationships between predictor and predicting variables. The factors 'vertical coordination', 'negotiation power' and 'IOS use' were designed as exogenous variables that influence 'inter-firm relationship strength' and 'SC Performance', while the emanating path from 'relationship strength' was designed to investigate the extent to which it is a source of SC Performance.

At the construct level, there are three second order multidimensional latent constructs named as 'Vertical Coordination', 'Relationship Strength' and 'SC performance' modelled as being caused by their first order latent variables or sub-constructs. A second order construct was modelled as being at a higher level of abstraction and created using linear composites from the items used to measure each sub-constructs (Rai, Patnayakuni, and Seth 2006).

\section{Survey Procedure and Sample}

The current study used a combination of field study, expert reviews and pilot study methods for developing the questionnaire and pretesting the survey.. After making necessary adjustments to the questionnaire and the measures, final data are collected using a computer-aided telephone interviewing system (CATI). A seven point Likert scale ranging from 'strongly disagree' to 'strongly agree' or 'Never' to 'Always' is used without mentioning any mid-point. Sample respondents were categorized as beef-cattle producers, processors, retailer/exporters, wholesalers and input suppliers. A minimum of 30 and a maximum of 100 responses were targeted for each of the three main categories of producer, processor and retailer firms (one response per firm with the person holding the highest position) in each of the two Australian states: Western Australia (WA) and Queensland (QLD). Thus, 315 responses from the beef industries in WA and QLD in Australia were eventually obtained. The responses showed that majority $(43.2 \%)$ of the firms were producers, processors $(28.9 \%)$ and retailers $(21.9 \%)$; the remaining firms were wholesaler and input suppliers.

\section{DATA ANALYSIS AND RESULTS}

Partial least squares (PLS), a confirmatory second-generation multivariate analysis tool, was used to test the hypotheses. The following two required steps for data analysis in PLS were conducted using PLS-Graph version 3.0.

\section{Assessment of the Measurement Model}

The individual item reliability was assessed by examining the loading or simple correlations of the measures with their respective constructs. The initial model was tested using 32 observed variables. The results of the initial model showed that four items had loadings below the acceptable standard (less than 0.6) which were removed from further analysis to improve the item reliability. Result also showed that all the latent variables have acceptable internal consistencies of above 0.7 and an AVE (Average Variance Extracted) over 0.5 (Barclay, Higgins, and Thompson 1995). We also checked the discriminant validity of the constructs and found that all the variables demonstrate acceptable performance on this basis. To measure the second-order formative constructs, linear composites of the items measuring each of the first-order constructs was used as a formative indicator. The result indicated that all the first-order constructs, except that the contractual arrangement, have a significant formative weight for their respective second-order construct. 


\section{Structural Model and Test of Hypothesis}

The coefficient of each hypothesized path and its corresponding t-value obtained from the 100-sample bootstrap procedure in PLS are shown in Table 1. It reveals that all of the paths, except the effect of IOS use on SC performance, have a significant loading (standardized $\beta \mathrm{s}$ ) and $\mathrm{t}$-values and thus provides support for the hypotheses at $\mathrm{P}<0.000$ and $\mathrm{P}<0.001$ level. The results reveal that negotiation power is the strongest predictor of relationship strength, followed by vertical coordination and IOS use across the supply chain. As the PLS result establishes the relative importance of the antecedent constructs by calculating all the indirect and direct effects of the latent construct (Barclay, Higgins, and Thompson 1995), results show that the total effect (indirect + direct) of 'relationship strength' strongly and significantly influences the supply chain performance in the industry.

\section{DISCUSSION AND IMPLICATIONS OF THE RESULTS}

The factors relevant to developing competent inter-firm relationships and their effect on a supply chain performance have been the focus of the paper. Six hypotheses were tested and the data supported acceptance of five of them. The findings revealed that, given the affect of all the antecedents and lower-order constructs, inter-firm relationship strength has a strong positive influence on supply chain performance (H6). The findings have significant implications for the improvement and management of the beef industry in Australia; the supply chain needs to be focused and leveraged to create performance gains by more formalized vertical interactions between the producers, processors and retailers.

The two hypothesized relationships ( $\mathrm{H} 1$ and $\mathrm{H} 2)$ of vertical coordination and relationship strength and vertical coordination and supply chain performance were strongly supported; they showed important implications: the level of coordination such as the sales and distribution of products, information sharing and asset specific investment; and, that the level of formalized transactions such as short-term and long-term contracts rather than open market transactions are significantly important in organizing and governing a vertical relationship. The evidence also support that vertical coordination can integrate supply chain members and can improve the information flow given that to a very limited extent, open markets are able to pass on quality-related information in food chains. For example, based on current market trends, a beef producer may need advance information on feeding, animal health and biological attributes of the product to make necessary adjustments in farming methods that lead to carcass development within a targeted range of quality and cost. On the other hand, processors and retailers need to know the quality attributes and markets of the products with detailed information about where and how the product was produced. Vertical organization and information sharing can integrate such knowledge from many different individuals in the supply chain and can provide a basis for a better performance of the supply chain.

The support of the hypothesis $\mathrm{H} 3$ between negotiation power and relationship strength is consistent with the literature, that without a bargaining or market power it is difficult to develop a lean partnership of associated trust, commitment and interdependence, especially where large firms extract as much value as possible from the supply chain transactions. The result has implications because of the nature of the beef industry power structures in WA and QLD and, generally, overall in Australia. The retailing chain in the Australian domestic market is dominated by the top two supermarket retailers Woolworths and Coles - both at the national and state levels. Together they maintain more than a 50 percent share of the market, which gives them the ability to dominate market prices (WAFarmers 2009). On the other hand, the vibrant export market for Australian beef has helped some processors, particularly in QLD, to dominate the processing sector and reduce some of the market power of supermarket retailers. Thus, overall, the Australian beef market has a high concentration of market power at the processor and retailer levels and is buyer dominant. At the same time, the relative power of farmers/producers typically depends upon supply scarcity. Unless they are in a long-term interdependent relationship, farmers tend to become price takers when there is sufficient supply. In this kind of buyer-dominated market, Cox and Chickland (2008) suggested that operational adoption of a lean supply chain is unlikely to be successful. Instead, it is feasible to develop lean partnerships between retailers and major processors or the processor and farmers where farmers and processors can get higher net returns by greater compliance with carcass specifications, alignment with market needs and by guaranteed supply.

The research model has provided strong support for the role of IOS in enhancing the level of relationship strength (H4) and have implication that IOS can be used to develop more cooperative and long-lasting relationships in the supply chain as it enhances access to the sources of knowledge, creates greater breadth and depth of information flows and develops other organizational competencies. But the data did not support the other hypothesized relationship (H5) between IOS and a supply chain, which is counterintuitive and contrary to what was expected according to the literature, although, this is not the only 
study where the uses of IOS in performance and competitiveness have being questioned. Based on empirical evidence, some studies claimed that IOS, especially EDI (Electronic Data Interchange), does not create differential benefits to firms and that vertical information sharing may not always increase the benefits (Premkumar 2000). It is argued that IOS by themselves cannot produce sustained performance advantages unless pre-existing complementary human and business resources are exploited in an integrated way as indicated by RBV (Powell and Dent-Micallef 1997). The implication from the overall findings, therefore, suggest that IOS use can produce sustainable advantage in supply chains when used as a complementary business resource in the presence of strong inter-firm relationships and information sharing attitudes. For improved information accuracy and improved ordering, processing and distribution of goods in the supply chain, the level and adoptability of IOS should be matched with the existing intimacy of the relationships and in the context of the beef supply chain.

Finally the model provides strong evidence that inter-firm relationship strength can strongly influence supply chain performance in the Australian beef industry. The result is consistent with the literature that a strong inter-firm relationship is considered as a value-creating strategic/economic resource that can contribute to firm performance. Relationship strength, based on joint ventures, interdependence, commitment and trust, enhances business transactions, minimizes the cost structure and improves the productivity and profitability of firms. The outcome is consistent with the literature that a long-term relationship emerges when one partner depends on another in a unique way and exhibits strong trust. Ultimately, this reduces costs over time at a rate comparable to sales growth (Clare, Reid, and Shadbolt 2005; Maloni and Benton 2000). For example, a committed and trusted long-term relationship can avoid the costs of monitoring true quality of beef, can reduce lead-time in sourcing and can ensure greater consistency of meeting market specifications. Thus, the empirical evidence of the impact of relationship strength and a deeper understanding of the elements of relational exchanges from this study have practical implications for emphasising relationship factors and improving the performance of a supply chain in the Australian beef industry.

\section{CONCLUSION}

This study examines how supply chain structures and inter-organizational relationship factors influence SC performance in the Australian beef industry. Using four elements of inter-firm relationships in a higher order formative construct, we investigated the extent to which the aggregated relationship strength is a source of supply chain performance for the industry. Results support both the direction of theoretical underpinning from RBV and TCE in beef industry in that durable buyersupplier relationships in the supply chain indeed develop from the levels of trust, commitment, interdependence and mutual investment; and that they can be a strategic weapon and economic resource to by-pass the cost of traditional market transactions. The operational adoption of a lean supply chain between producer and processors or processors and retailers, a transparent interdependent relationship with a strong consolidation/integration of business activities, and a synchronized information flow for greater compliance with carcass specifications in the supply chain are identified as key success factors for the beef industry in Australia.

\section{TABLES}

Table 1: Test of Hypotheses

\begin{tabular}{|c|l|c|l|l|}
\hline Hypothesis & \multicolumn{1}{|c|}{ Path } & $\beta$ & t-value & \multicolumn{1}{|l|}{ Outcome } \\
\hline H1 & Vert. coord. $\rightarrow$ Rel. strength & 0.196 & $3.505^{* * * *}$ & Supported \\
\hline H2 & Vert. coord. $\rightarrow$ SC Perf. & 0.224 & $3.854^{* * *}$ & Supported \\
\hline H3 & Neg. power $\rightarrow$ Rel. strength & 0.370 & $6.627^{* * * *}$ & Supported \\
\hline H4 & IOS Use. $\rightarrow$ Rel. Strength & 0.198 & $4.266^{* * *}$ & Supported \\
\hline H5 & IOS Use $\rightarrow$ SC perf. & 0.044 & 0.879 & Not supported \\
\hline H6 & Rel. strength $\rightarrow$ SC. Perf. & 0.298 & $5.067 * * *$ & Supported \\
\hline
\end{tabular}

*** $\mathrm{p}<0.000$ (two-tailed), $\quad \mathrm{R}^{2}$ for inter-firm relationship strength $=0.359, \mathrm{R}^{2}$ for supply chain performance $=0.214$ 


\section{FIGURES}

Figure 1: Model of Theoretical Relationships \& Measurement Items

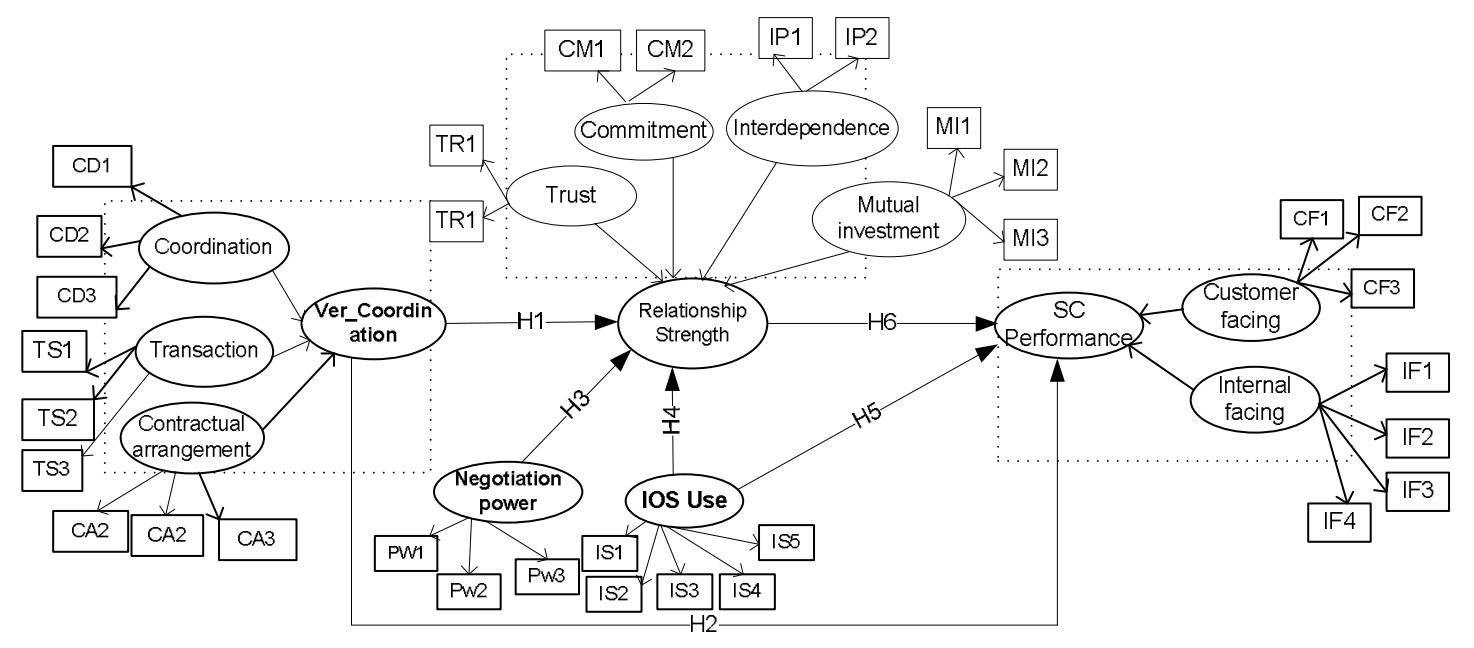

\section{REFERENCES}

Alavi, M. and D.E. Leidner. 2001. "Knowledge Management and Knowledge Management Systems: conceptual foundations and research issues." MIS Quarterly 25 (1): 107-136.

Ali, M., S. Kurnia and R.B. Johnston. 2007. "Interorganizational system (IOS) adoption maturity: a model and propositions." In Proceedings of European and Mediterranean Conference on Information Systems 2007 (EMCIS2007), June 24-26, Polytechnic University of Valencia.

Barclay, D., C. Higgins and R. Thompson. 1995. "The Partial Least Squares (PLS) Approach to Causal Modelling: Personal Computer Adoption and Use as an Illustration.” Technology Studies 2: 285-309.

Barney, J. B. 2002. Gaining and Sustaining Competitive Advantage, 2nd edn. Prentice-Hall; Upper Saddle River, NJ.

Borman, M. 2006. Developing and testing a theoretical framework for inter-organizational systems (IOS) as infrastructure to aid future IOS design. Springer-Verlag.

Chin, W. W. 1998. "Issues and Opinion on Structural Equation Modelling.” MIS Quarterly, 22: vii-xvi.

Clare, B. G., J .I. Reid, and N. M. Shadbolt. 2005. "Supply Base Relationships in the New Zealand Red Meat Industry: A Case Study." In Proceedings of the IAMA Fifth International Conference on Chain and Network Management in Agribusiness and the Food Industry. Wageningen: Netherlands.

Cox A. and D. Chicksand. 2008. "Rethinking Policy Options for Industry: Appropriateness in Policies for Industry and UK Farming and Food." Public Administration 86 (3): 813-836.

Golicic, S. L., J. H. Foggin and J. T. Mentzer. 2003. "Relationship magnitude and its role in interorganizational relationship structure." Journal of Business Logistics 24 (1): 57-75.

Hobbs, J. E. and L.M. Young. 2000. "Closer Vertical Coordination in Agri-food Supply Chains: A Conceptual Framework and Some Preliminary Evidence.” Supply Chain Management 5 (3): 131-142. 
Lawrence, J., G. Grimes and M. Hayenga. 1998. Production and marketing characteristics of U.S. pork producers, 19971998. Iowa State University and University of Missouri.

Maloni, M. and W.C. Benton. 2000. "Power influences in the supply chain.” Journal of Business Logistics 21 (1): 49-73.

O'Keeffe, M. 1998. "Establishing supply chain partnerships: lessons from Australian agribusiness.” Supply Chain Management: An International Journal 3 (1): 5-9.

Peterson, H. C. and A. Wysocki. 1997. "The Vertical Coordination Continuum and the Determinants of Firm-Level Coordination Strategy." Staff Paper, No. 97-64, Michigan State University.

Powell, T. C. and A. Dent-Micallef. 1997. "Information technology as competitive advantage: the role of human, business, and technology resources." Strategic Management journal 18(5): 375-405.

Premkumar, G.P. 2000. "Interorganization systems and supply chain management: An information processing perspective", Information Systems Management 17(3): 56-69.

Rai, A., R. Patnayakuni and N. Seth, 2006. "Firm performance impacts of digitally enabled supply chain integration capabilities," MIS Quarterly 30 (2): 225-246.

Revell, B. J. and X. Liu. 2007. "Chain Management Challenges and Market Power in the Chinese Fresh Produce Sector". In: International Agri-food Chains and Networks: Management and Organisations. Eds Bijman J., O. Omta, J. Trienekene, J. Wijnands and E. F. M. Wubben, Wegeningen Academic, Netherlands.

Uddin, M. N., M. Quaddus and N. Islam. 2010. "Knowledge asset and inter-organizational relationship in the performance of Australian beef supply chain", In Proceedings of the Pacific Asia Conference on Information systems (PACIS), July 2010: 725- 737.

WAFarmers. 2009. Supply Chain Analysis for Retail Competitiveness. a Submission presented by the Pastoralists and Graziers Association of Western Australia and the Western Australian Farmers Federation on behalf of the Livestock Industry of Western Australia. Retrieved from http://www.wafarmers.org.au/contact/default.asp

Williamson, O. E. 1975. Markets and Hierarchies. New York: Free Press.

Williamson, O. E. 1985. The Economic Institutions of Capitalism. New York: Free Press.

WY \& Associate. 2009. Objective Assessment of the West Australian Beef Industry Supply Chain: Report 1-Issue paper, Prepared for WA Beef Industry Stock take Committee, Warwick Yates \& Associates. 